\title{
Capítulo 4 \\ Reconciliación y perdón en dos comunidades colombianas víctimas de la violencia
}

Edgar ANTONIo LÓPEZ López

Este capítulo presenta algunos resultados de la investigación "Creer en la reconciliación”, desarrollada por Henk Vijver y Edgar Antonio López, entre mayo de 2012 y junio de 2015, con la participación de la Asociación de Familiares de las Víctimas de la Masacre de Trujillo (AFAVIT), en el Valle del Cauca, y los miembros de la Iglesia "Hermanos Menonitas" de Pie de Pepé, en el Chocó. Realizada gracias a la cooperación entre diferentes iglesias cristianas de Colombia y de los Países Bajos, la investigación tuvo como objetivo articular la reflexión académica sobre la reconciliación y la reflexión experiencial de comunidades de base, cuyos derechos fundamentales hubiesen sido objeto de vulneración por parte de actores armados.

Mediante la lectura comunitaria de tres narraciones bíblicas relacionadas con la reconciliación, desde sus experiencias traumáticas, los miembros de las comunidades involucradas contribuyeron a establecer cuáles son las posibilidades reales de reconciliación en casos tan complejos como los de las masacres y los desplazamientos forzados. Fueron varias las comunidades convocadas a participar en la investigación, pero solo dos de ellas terminaron el proceso mediante la realización completa de una serie de tres talleres bíblicos. 


\section{Las comunidades participantes}

La primera comunidad que participó en la investigación fue un grupo de veinticinco personas pertenecientes a la Asociación de Familiares de las Víctimas de la Masacre de Trujillo (AFAVIT), organización conformada en 1995 por las familias de las víctimas de esta masacre.

Con el propósito de eliminar la presencia del Ejército de Liberación Nacional (ELN) en la zona, en el marco de la guerra contrainsurgente al final de los años 80 y el inicio de los años 90, algunos miembros de la policía y del ejército establecieron una alianza con grupos criminales del narcotráfico, desencadenando así una práctica sistemática de desapariciones, torturas y asesinatos en la región. Alrededor de cuatrocientas personas, acusadas de colaborar con esta guerrilla, murieron en forma violenta al ser objeto de prácticas particularmente crueles. En muchos casos, la sevicia de los perpetradores de la masacre no solo acabó con las vidas de estas personas, sino destruyó sus cuerpos, cuyos despojos fueron arrojados al río Cauca (Grupo de Memoria Histórica, 2011).

Desde entonces, los familiares de las víctimas de esta masacre han adelantado una ejemplar lucha por la justicia, la memoria de sus seres queridos, la reparación integral y las garantías de no repetición. Como parte de la reparación ordenada por la Corte Interamericana de Derechos Humanos, AFAVIT recibió del Estado colombiano un lote en una colina del casco urbano en el que, gracias a la contribución de agencias nacionales e internacionales, construyó un parque memorial en medio del cual edificó un espacio para alojar una galería de la memoria y un archivo documental. En este lugar, fueron desarrollados los talleres bíblicos.

La segunda comunidad participante en la investigación vive en la región selvática chocoana del Medio Baudó, en la parte alta del río Pepé. En agosto de 2010, luego de la desaparición de tres habitantes, alrededor de trescientas personas fueron desplazadas del caserío Unión Berrecui por la acción violenta de grupos paramilitares. A diez kilómetros de camino, estas personas fueron acogidas por los habitantes de Pie de Pepé.

Quienes dejaron todo lo que tenían para refugiarse, inicialmente pensaron que pronto podrían regresar a su territorio, bañado por la quebrada Berrecui. Sin embargo, la presencia de los grupos armados en la zona impidió su retorno y la convivencia con quienes los habían 
acogido en las orillas del río Pepé se hizo más difícil, conforme transcurrió el tiempo.

Esta segunda comunidad está compuesta entonces por dos grupos, a saber: los pobladores originarios de Pie de Pepé y las personas que huyeron hasta allí para poner a salvo sus vidas. Antes del desplazamiento, había buenas relaciones entre ambas poblaciones, pero por tratarse de una zona muy aislada, con servicios limitados y precaria infraestructura, surgieron tensiones que deterioraron el tejido social y terminaron por generar polarización política entre los habitantes.

En las modestas instalaciones de la Iglesia "Hermanos Menonitas", en la ribera del río, un grupo de veinticinco personas, provenientes tanto de Unión Berrecui como de Pie de Pepé, participó en los talleres bíblicos, que varias veces debieron ser aplazados por razones de seguridad, y el ciclo terminó solo en junio de 2015.

Las dos comunidades están conformadas por personas de diferentes edades, que van desde jóvenes hasta ancianos. En su mayoría los participantes son de origen campesino y tienen diferentes grados de escolaridad, que en ambos casos incluyen personas que no saben leer ni escribir.

\section{El método}

Antes de comenzar con los talleres fue necesario hacer varias visitas a las comunidades para crear confianza y ayudarles a comprender tanto la naturaleza como los propósitos de la investigación. Esta fase previa reviste gran importancia por tratarse de comunidades vulnerables, que han sido objeto de estudio e intervención por parte de diferentes organizaciones.

Los miembros de estas comunidades han sido instrumentalizados varias veces como fuentes de información y sus datos personales han servido para levantar registros orientados inescrupulosamente a la captación de recursos económicos, sin haberse beneficiado en absoluto de su participación. Por esta razón, hay mucha desconfianza frente los miembros de organizaciones externas.

Los textos para los talleres fueron elegidos por los investigadores, luego de haber consultado con las comunidades sobre sus necesidades y sus expectativas. El primer texto bíblico empleado en Trujillo narra el 
encuentro de Pablo de Tarso con Ananías, una de sus potenciales víctimas, quien le devuelve la vista (Hch 9,1-19). La segunda narración cuenta la historia de cómo Jacob, años después de haber tenido que huir por arrebatarle engañosamente a su hermano Esaú los derechos de primogenitura, regresa lleno de temor y es recibido por este sin rencor y sin venganza (Gn 32,4-32; 33,1-4). En el tercer texto, Jesús narra la historia del hijo mayor que no comprende cómo su padre se alegra y hace una fiesta por el regreso del hijo menor, quien se había malgastado la herencia, mientras el hijo mayor ha estado siempre cumpliendo sus deberes en la casa del padre (Lc 15, 11-32). En Trujillo los talleres fueron realizados en octubre de 2012, abril de 2013 y julio de 2013.

En Pie de Pepé los talleres se basaron en los mismos textos, pero el orden fue modificado para atender mejor a lo que la comunidad estaba viviendo, por las tensiones entre la población que debió desplazarse y la población receptora. En este caso, la serie de talleres comenzó con la narración lucana sobre el hermano mayor, luego siguió con la historia de Pablo y Ananías, para terminar con la narración del encuentro entre Jacob y Esaú. Estos talleres fueron realizados en noviembre de 2013, noviembre de 2014 y junio de 2015.

La lectura de estos relatos bíblicos se hizo con base en el supuesto teórico según el cual el sentido de los textos no está en ellos mismos, sino que se despliega delante de ellos al ser interpretados por sus lectores y lectoras. "Lo que se ha de comprender en un relato no es en primer lugar a aquel quien habla detrás del texto, sino aquello de lo que se habla, la cosa del texto, a saber, el tipo de mundo que la obra despliega de alguna manera delante del texto" (Ricœur, 1986, p. 187).

El mundo del texto se revela entonces a quienes lo leen como la posibilidad de dar origen a nuevos mundos, que son posibles a través de diferentes cursos de acción, pues la ficción narrativa reconfigura la realidad práctica. "El texto se dirige intencionalmente a un horizonte de realidad nueva que podríamos llamar un mundo. Es este mundo del texto el que interviene en el mundo de la acción para configurarlo de nuevo, o si nos arriesgamos a decirlo, para transfigurarlo" (Ricœur, 1986, p. 27).

Debido a la tensión entre el texto y la experiencia vital de la comunidad que lo lee, el mensaje liberador de los textos sagrados es 
interpretado a la luz de la historia y esta lo es a la luz de tal mensaje, en una relación dialéctica que se concreta como práctica en la acción de la comunidad (López, 2009).

De acuerdo con esta mutua implicación entre el texto y la vida, los talleres fueron estructurados con base en las preguntas: ¿De qué trata el texto?, ¿Cuáles son los personajes de la historia?, ¿Qué hacen?, ¿Cómo se sienten?, ¿Qué dicen?, ¿Con cuáles de estos personajes se identifican ustedes?, ¿Conocen ustedes historias parecidas?, ¿Pueden compartirlas con el grupo?

El análisis de la información recogida en los talleres bíblicos se hizo desde la perspectiva hermenéutica de la apropiación, un enfoque particularmente fecundo en la teología latinoamericana. "La referencia original pierde su importancia en beneficio del sentido (lo dicho del texto) y un nuevo contexto, actualizado por el nuevo lector o la nueva lectora" (De Wit, 2002).

Se trata de un modo propicio de aproximarse al proceso interpretativo de las Sagradas Escrituras, cuando se pretende captar cómo la comunidad establece una relación entre el texto bíblico y su propia vida, no solo para asumir su realidad, sino para transformarla.

\section{Los resultados}

La actualización de los textos bíblicos hecha por los miembros de AFAVIT mostró cómo, al menos para este caso, el diseño investigativo había sido demasiado amplio, toda vez que las experiencias reales de reconciliación han sido muy escasas, por requerir no solo el concurso de quienes han padecido los efectos de la violencia, sino la participación de los victimarios. En contadas ocasiones, los perpetradores de desapariciones, torturas y asesinatos han propiciado encuentros con los familiares de las víctimas.

Hasta donde se pudo establecer durante los talleres, en tales encuentros las víctimas siempre estuvieron dispuestas a dialogar con quienes les habían causado daño. Sin embargo, la experiencia de los integrantes de AFAVIT ha estado más relacionada con el perdón, que puede considerarse como una fase previa a una posible reconciliación. Gestos subrayados por las narraciones bíblicas, tales como el abrazo entre hermanos o el abrazo entre padre e hijo, nunca serán posibles 
entre las víctimas y los victimarios que conviven en el pueblo. No obstante, la posibilidad de reconstruir la propia vida constituye una razón permanente para perdonar.

Las narraciones hechas por los participantes de Trujillo a la luz de las narraciones bíblicas pusieron en evidencia que el perdón es un proceso difícil, pero que no es imposible. El tiempo transcurrido desde que los hechos violentos fueron cometidos les ha ayudado a perdonar, pero también es muy importante ese tiempo que aún está por venir, en el que todavía es posible construir una nueva vida.

Sin claudicar en su lucha por la justicia, la memoria, la reparación y las garantías de no repetición de los hechos violentos, la mayor parte de los miembros de AFAVIT han podido perdonar a quienes les causaron profundo dolor. Se trata de haber hecho posible la reconstrucción de su propia vida, a partir de un cambio de perspectiva que les permite ver de otra manera su dolor sin olvidarlo (López, 2013).

Detrás de este cambio de perspectiva, hay un proceso de autotransformación facilitado no solo por procesos de acompañamiento profesional y de escucha por parte de personas externas, sino por la experiencia de la unión y la solidaridad entre los miembros de la misma asociación. De acuerdo con los participantes vallecaucanos, tales experiencias son expresión del amor, que consideran la misma fuente del perdón y de la reconciliación (López, 2014).

Los miembros de esta comunidad tienen ante sí tres desafíos. El primero consiste en superar la visión de los procesos judiciales y de las sentencias proferidas como una forma de retaliación contra quienes cometieron la masacre. El segundo, se trata de no agotar su propio ser en su condición de víctimas, algo que ha terminado por configurar su existencia y que puede impedirles tanto el ejercicio como la justa valoración de otros roles sociales. En tercer lugar, es su deber mantener viva la memoria de sus seres queridos, pero también es su deber no dejarse atrapar por el pasado y proyectar un futuro mejor para ellos y para las siguientes generaciones de trujillenses.

En el caso de la comunidad de Pie de Pepé, el principal desafío es el de superar la división, pues las difíciles condiciones en que las personas deben sobrevivir generan tensiones asociadas al ejercicio de actividades económicas de subsistencia, tales como la minería, o 
relacionadas con el apoyo a unos y a otros líderes políticos que hacen promesas en épocas electorales.

Durante los talleres bíblicos, se manifestó con frecuencia cómo cuando las dos poblaciones que conforman la comunidad vivían separadas, se vivía la fraternidad entre ellas y ahora, cuando ocupan el mismo espacio, también deberían convivir como las hermanas y los hermanos que son.

Tal como en el caso de Trujillo, el temor y la incertidumbre asociada a él fueron sentimientos compartidos que permitieron a los participantes de Pie de Pepé identificarse con Ananías, a quien Pablo perseguía, y también con Jacob, quien esperaba la inminente venganza de su hermano. La superación de ese temor fue asociada por los participantes chocoanos con una transformación de la propia persona; en este caso, producida por la fe y propiciada también por una transformación de quienes ejercían violencia, como Pablo, o de quienes vivían del engaño, como Jacob.

El carácter restaurador de la reconciliación fue más evidente para los participantes de Pie de Pepé, quienes prestaron particular atención a las relaciones fraternas rotas por las acciones de los personajes de las narraciones, como en su propia vida lo hicieron quienes causaron su desplazamiento forzoso. Mientras tanto, los miembros de AFAVIT asociaron la restauración del tejido social a su propio trabajo por la memoria, la justicia, la reparación y la no repetición de los hechos violentos.

La reparación ofrecida por Jacob para apaciguar la ira de Esaú fue asociada por los miembros de las dos comunidades con la reparación que los victimarios y el Estado ofrecen a las víctimas. En ambos casos se prestó atención a la intención instrumental que puede estar detrás de estas acciones compensatorias. En este sentido, se advirtió sobre la importancia de no aceptarlas como el precio que se paga por el silencio o por el abandono de la lucha por la justicia.

El perdón del padre en la historia contada por Jesús fue una invitación a los miembros de ambas comunidades para fijarse menos en los actos violentos que los agentes armados han cometido contra ellos y prestar más atención a sus propias limitaciones personales y comunitarias. El horizonte teológico de su reflexión es el de una justicia fundada en la misericordia y no en el castigo. Eso sería para ellas 
recobrar la vista, como Pablo, y cambiar de nombre, como Jacob, quien luego se llamaría Israel.

\section{Comentarios finales}

La reconciliación es una experiencia compleja, que depende tanto de la voluntad de quienes han padecido la violencia como de quienes la han generado. El perdón, en cambio, puede ser otorgado por las víctimas, aun sin que haya sido pedido por quienes han producido sufrimiento o sin que hayan asumido su culpa de manera manifiesta (López, 2014). Para que haya reconciliación, en cambio, es necesario el perdón efectivo de unos y el arrepentimiento sincero de otros.

Se puede hablar de perdón como la superación unilateral del daño infligido por otros. La acción generosa de quienes, habiendo padecido el mal, renuncian a devolverlo se revela entonces como per-donar. Se trata de un don gratuito otorgado libremente al agente por parte de la víctima, quien no solo libera al perpetrador de la posibilidad de venganza, sino que se libera a sí mismo de la prolongación de la acción perjudicial en el tiempo (López, 2014), al prescindir del recurso a la retaliación y sobreponerse al rencor derivado de su resentimiento.

Hacer daño a otra persona es establecer con ella una relación de subordinación mediante el ejercicio de un poder destructivo, pero la capacidad de quien ha quedado sometido para suspender la continuidad de tal vejación se manifiesta en la posibilidad de incorporar tal experiencia a su propia biografía y sobreponerse al daño infligido mediante un cambio de perspectiva, que en adelante permita recordar el mal padecido sin prolongarlo en el tiempo (López, 2013).

Perdonar libera a ambas partes de las consecuencias de una acción dañina, interrumpiendo su continuidad al poner un límite en el tiempo (Arendt, 1998). El perdón no solo beneficia a quienes han padecido el mal, sino a la sociedad en la que este se ha alojado por las acciones de algunos, pues perdonar es romper los círculos de violencia en que algunas sociedades han quedado atrapadas (López, 2014).

En el estudio de experiencias traumáticas, en las cuales unas personas han producido sufrimiento a otras, existe el riesgo de la ontologización, expresado aún en el uso de términos como "víctima" 
y "victimario", o en la diferenciación desprevenida que se hace entre unas personas "buenas" y unas personas "malas". La ontologización de unas personas como víctimas y de otras como victimarios es una simplificación que pierde de vista la importancia de los papeles que juegan los individuos en el entramado de relaciones sociales.

El uso de la palabra "malo" como predicado simple puede ser aplicado a una mala acción o al agente de tal acción (Tugendhat, 1990), así es como se establece una asociación entre la maldad de una acción y la maldad del sujeto que la comete. No obstante, aun si se trata de un mal ciudadano o un mal miembro de la comunidad, los parámetros morales que permiten establecer la maldad de una acción no son suficientes para sostener el enunciado ontológico según el cual el agente sea una mala persona. "No hay personas buenas y personas malas; solo hay personas que hacemos cosas buenas y cosas malas” (López, 2014, p. 166).

La posibilidad de otorgar el perdón depende del poder para diferenciar entre la acción y el agente. Se trata de reconocer la humanidad del agente, sin desconocer la relación de responsabilidad que lo liga a sus malas acciones. Tales acciones deben ser objeto de crítica y sus autores deben ser objeto de reprobación (Tugendhat, 1990, p. 6), pero esto no implica transferir la maldad de las acciones a los autores de ellas.

Una persona que puede ser reconocida como víctima en un marco relacional determinado, por ejemplo, un campesino que ha sufrido desplazamiento forzado en el caso del conflicto armado, puede serlo también como victimario en otro marco de referencia, como el de sus relaciones familiares en el caso de violencia doméstica. Son las relaciones que establecemos con otras personas las que determinan el daño que podemos padecer o el que podemos causar a otros.

Perdonar implica diferenciar la maldad de las acciones cometidas y la condición humana de quienes las han puesto por obra. Es reconocer que en los agentes siempre habrá una reserva de humanidad, que "algo del sujeto está exento, que habría podido no ser disipado en la adhesión de la voluntad al mal cometido" (Ricœur, 2000, p. 602).

Las partes de las dos comunidades que participaron en esta esta investigación implican adoptar un cambio de perspectiva para aceptar una justicia en que haya oportunidades para quienes obran rectamente, pero también para aquellos que no han obrado de esa manera. 
Colombia requiere una justicia que restaure el daño histórico hecho por la violencia y que no profundice el dolor o promueva la venganza. Se trata de una justicia que allane el camino hacia la reconciliación y que permita vivir el perdón como liberación. En esto consiste aceptar los límites de la institucionalidad convencional y reconstruirla a partir del reconocimiento de la humanidad.

\section{Referencias}

Arendt, H. (1998). The human condition (2.a ed.). Chicago: The University of Chicago Press.

De Wit, H. (2002). En la dispersión el texto es patria. Introducción a la hermenéntica clásica, moderna y posmoderna. San José de Costa Rica: Universidad Bíblica Latinoamericana.

Grupo de Memoria Histórica. (2011). La masacre de Trujillo. Una tragedia que no cesa. Bogotá: Comisión Nacional de Reparación y Reconciliación.

López, E. (2009). La evangelización como práctica interpretativa. Bogotá: Pontificia Universidad Javeriana.

López, E. (2013). Perdonar sí, olvidar no. Universitas Philosophica, 61, 85-96.

López, E. (2014). Perdón, memoria y justicia. Proyección teológica de la reconciliación en Colombia. En E. Vijver \& E. López (Dirs.), Creer en la reconciliación (pp. 145-176). Bogotá: Editorial Pontificia Universidad Javeriana.

López, E. (septiembre, 2015). Reconciliación, memoria y justicia en Colombia. Trabajo presentado en el XIII Congreso La Investigación en la Pontificia Universidad Javeriana, Bogotá, Colombia.

Ricoeur, P. (1986). Du texte à l'action. Essais d'herméneutique II. París: Éditions du Seuil.

Ricoeur, P. (2000). La mémorie, l'histoire, l'oubli. París: Éditions du Seuil.

Tugendhat, E. (1990). El papel de la identidad en la constitución de la moralidad. Ideas y Valores, 39, 3-14. 



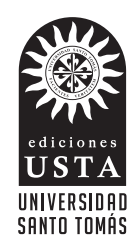

Esta obra se editó en Ediciones USTA,

Departamento Editorial de la Universidad Santo Tomás.

Se usó papel propalcote de 300 gramos para la carátula y papel bond beige de 75 gramos para páginas internas.

Tipografía de la familia Sabón. Impreso por Digiprint Editores S.A.S. 2017. 
El perdón ha sido un elemento fundamental del paisaje moral y religioso en la tradición judeocristiana. En nuestro contexto, el perdón recientemente ha ganado protagonismo por su importancia en los acuerdos de paz, en los procesos de reconciliación y en las políticas de justicia transicional con los que se ha buscado poner fin a periodos prolongados de violencia. Este libro explora la cuestión del perdón con un carácter decididamente interdisciplinario. Aborda la dimensión filosófica del perdón e incursiona luego en el terreno empírico a través de tres objetos específicos. Desde un enfoque jurídico, presenta una interpretación de los textos legales con los cuales el gobierno colombiano le ha dado un puesto destacado en la vida nacional. Con los recursos conceptuales y metodológicos de la antropología, hace una lectura crítica de las declaraciones y demandas de perdón de uno de los más reconocidos victimarios paramilitares. Por último, desde la iluminación bíblica y teológica, describe un trabajo de campo con dos comunidades golpeadas por la violencia. El libro que aquí se ofrece motivará a sus lectores para que asuman su responsabilidad frente a las víctimas del pasado y del presente. 